\title{
Worldwide Implications of Multiple Acceptance and Rejection on the Psychological Adjustment and Maladjustment of Children and Adults: A Global Multi-Cultural Study
}

\author{
Abdul Khaleque ${ }^{1 *}$, Farah Deeba ${ }^{2}$ and Nafisa Banoo ${ }^{3}$ \\ ${ }^{1}$ Department of Human Development and Family Sciences, University of Connecticut, USA. \\ ${ }^{2}$ Department of Clinical Psychology, University of Dhaka, Bangladesh. \\ ${ }^{3}$ Hillview Mental Health Center, Pacoima, CA, USA.
}

*Correspondence Author: Abdul Khaleque, Department of Human Development and Family Sciences, University of Connecticut, USA. Received date: April 01, 2021; Accepted date: April 25, 2021; Published date: May 08,2021

Citation: Khaleque A., Deeba F. and Banoo N. (2021) Worldwide Implications of Multiple Acceptance and Rejection on the Psychological Adjustment and Maladjustment of Children and Adults: A Global Multi-Cultural Study. Clinical Medical Reviews and Reports 3(5); DOI: $10.31579 / 2690-8794 / 079$

Copyright: (C2021 Abdul Khaleque, Farah Deeba and Nafisa Banoo, This is an open access article distributed under the Creative Commons Attribution License, which permits unrestricted use, distribution, and reproduction in any medium, provided the original work is properly cited.

\section{Abstract}

The objectives of this study were to explore the combine effects on children's psychological adjustment and maladjustment of perceived acceptance or rejection by mothers, fathers, and teachers; and also to examine the combine effects on adults' current psychological adjustment and maladjustment of perceived acceptance or rejection by mothers and fathers in childhood and by intimate partners in adulthood. The samples consisted of 586 children ( $47 \%$ boys and $53 \%$ girls) and 1,709 adults (35\% males and $65 \%$ females). Among the children 573 were in the multiple acceptance group and 13 were in the multiple rejection group, and among the adults 1,645 were in the multiple acceptance group and 64 were in the multiple rejection group. The samples were selected from 11 countries in four continents. Results showed that significantly more girls than boys, and more women than men experienced multiple acceptance. Regardless of age, gender, and culture, the majority of sample in the multiple acceptance group reported healthy psychological adjustment, and the majority of respondents in the multiple rejection group reported moderate to severe psychological maladjustment. Results also showed a significant tendency for adults to experience more rejection by all attachment figures than did children regardless of culture and gender.

Keywords: multiple acceptance- rejection, psychological adjustment-maladjustment, attachment figures

\section{Introduction}

A great deal is known about the cross-cultural effects of perceived rejection of children by their attachment figures such as mothers, fathers, and teachers (e.g., Erkman, Caner, Sart, Borkan, \& Sahan,2010; Rohner, Khaleque, Elias, \& Sultana, 2010); and perceived rejection of adults by their attachment figures such as mothers, fathers, and intimate partners (e.g., Khaleque, Rohner, \& Laukkala, 2008; Ripoll-Nunez \& Alvarez, 2008; Rohner, Uddin, Shamsunnaher, \& Khaleque, 2008).

On the basis of findings of a number of case studies, Heller (2009) observed that convergence of childhood parental rejection coupled with adult interpersonal rejection may result in rejection crisis leading to severe psychological maladjustment. But little is known about the combined effects of perceived rejection by multiple attachment figures. The present study examined children's and adults' perception of psychological adjustments or maladjustment when they perceived themselves to be rejected (vs accepted) by their attachment figures.

\section{Method}

\section{Participants}

The participants consisted of 586 children (47\% boys and $53 \%$ girls) and 1,709 adults (35\% male and $65 \%$ female). Among the children $573(98 \%)$ were in the multiple acceptance group and $13(2 \%)$ in the multiple rejection group. Among the adult participants 1,645 (96\%), were in the multiple acceptance group and $64(4 \%)$ in the multiple rejection group. The samples were selected from 11 countries including Bangladesh, Colombia, Estonia, Finland, India, Japan, Korea, Kuwait, Puerto-Rico, Turkey, and the USA. The mean age of the children was 13 years and their age ranged from 10 through 16 years. The educational level of the children was $4^{\text {th }}$ through $10^{\text {th }}$ grades. The mean age of the adult participants was 25 years and their age ranged from 17 through 67 years. Majority of the adult participants were university students.

\section{Procedure}

The data for the present study were collected from the data archived in the Ronald and Nancy Rohner Center for the Study of Interpersonal Acceptance and Rejection at the University of Connecticut. Measures used for assessing multiple acceptance and rejection of children were the Child versions of the Parental Acceptance-Rejection Questionnaires for Mothers and for Fathers (Child PARQ: Mothers and Fathers) (Rohner, 1990), and the Child version of the Teacher's Acceptance-Rejection Questionnaire (Child TARQ) (Rohner, 2005). Measures used for assessing multiple acceptance and rejection of adults were the Adult versions of the Parental Acceptance-Rejection Questionnaires for Mothers and for Fathers (Adult PARQ: Mothers and Fathers) (Rohner, 
1990), and the Intimate Partner Acceptance-Rejection Questionnaire (IPAR) (Rohner, 2005). The participants were divided into multiple acceptance and rejection groups on the basis of cut off points of their scores on the measures used for the children and adult participants. For example, the children whose scores were below the midpoints on each of the Child PARQ: Mothers and Fathers, and the Child TARQ questionnaires were placed in the multiple acceptance group, and the children whose scores were at or above the midpoint on each of these questionnaires were placed in the multiple rejection group. Similarly, the adult participants whose scores were below the midpoints on each of the Adult PARQ: Mothers and Fathers, and the Intimate Partner Acceptance - Rejection (IPAR) questionnaires were placed in the multiple acceptance group, and the adults whose scores were at or above the midpoint on each of these questionnaires were placed in the multiple rejection group. The psychological adjustment of the children and adults were measured using the Child and Adult versions of the Personality Assessment Questionnaire (Child and Adult PAQ) respectively. The children and adults were divided into relatively well adjusted and maladjusted categories on the basis of the midpoint of their scores on the Child PAQ and Adult PAQ respectively. Both children and adults whose scores were below the midpoint of the PAQ were placed in the well-adjusted category and whose scores were at or above the midpoint were placed in the maladjusted category.

\section{Results}

The results showed that the mean psychological adjustment score of the rejected group of children is well above the test midpoint, indicating serious psychological maladjustment. Difference between the mean psychological adjustment scores of the accepted and rejected groups is highly significant $(t=4.60, d . f .=584, p<.001)$. Similarly, the mean psychological adjustment score of the rejected group of adults is well above the test midpoint, indicating serious psychological maladjustment. Difference between the mean psychological adjustment scores of these two groups is highly significant $(t=18.88$, d.f. $=1686, p<.001)$. Results further showed that significantly more girls (98\%) than boys $(97 \%)$ and more women $(98 \%)$ than men $(94 \%)$ experienced multiple acceptance and significantly more boys $(3 \%)$ than girls $(2 \%)$ and more men $(6 \%)$ than women $(2 \%)$ experienced multiple rejection. Moreover, the results also revealed that significantly more adults $(4 \%)$ reported rejection by multiple attachment figures than did children $(2 \%)$, regardless of gender and culture. In addition, the results showed that the great majority of both men $(72 \%)$ and women $(68 \%)$ of the multiple acceptance group reported healthy psychological adjustment. Contrarily, the great majority of both men $(71 \%)$ and women $(60 \%)$ of the multiple rejection group reported serious psychological maladjustment.

The overall results clearly showed that---regardless of culture, gender, ethnicity, and geographical boundary---both children and adults, who experienced more multiple rejection than acceptance from their attachment figures, suffered from a significantly high degree of psychological maladjustment than did children and adults who experienced more multiple acceptance than rejection.

\section{Conclusion}

The findings may be interesting and useful to researchers and practitioners who work on the problems of attachment relationships, psychological adjustment, and behavioral functioning of children and adults across culture. It seems interesting, as noted earlier, that on the basis of findings of a few case studies, Heller (2009) observed that convergence of childhood parental rejection coupled with interpersonal rejection during adulthood often results in a rejection crisis leading to severe psychological maladjustment, personality disorder, and violent behavior.

\section{References}

1. Erkman, F., Caner, A., Sart, H., Borkan, B., \& Sahan, K. (2010) Influence of perceived teacher acceptance, self-concept, and school attitude on the academic achievement of school-age children in Turkey. Cross-Cultural Research, 44(3), 295-309.

2. Heller, C. H. (2009) Applications of parental acceptance-rejection theory and evidence to forensic psychology. Interpersonal Acceptance, 3, 1-3.

3. Khaleque, A., Rohner, R. P. \& Laukkala, H. (2008) Intimate partner acceptance parental acceptance, behavioral control, and psychological adjustment among Finnish adults in ongoing attachment relationships. Cross-Cultural Research, 42, 35 - 45.

4. Ripoll-Nunez, K., \& Alvarez, C. (2008) Perceived intimate partner acceptance, remembered parental acceptance, and psychological adjustment among Colombian and Puerto Rican youths and adults. Cross-Cultural Research, 42, 23-34.

5. Rohner, R. P. (1990) Handbook for the study of parental acceptance and rejection. Storrs, CT: University of Connecticut.

6. Rohner, R. P. (2005) Parental Acceptance-Rejection/Control Questionnaire (PARQ/Control): Test manual. In R. P. Rohner \& A. Khaleque (Eds.) Handbook for the study of parental acceptance and rejection, 4th ed. (pp. 137-186). Storrs, CT: Rohner Research Publications.

7. Rohner, R. P., Khaleque, A., Elias, S., and Sultana, S. (2010) Relationship between perceived teachers and parental acceptance, school conduct and psychological adjustment of Bangladeshi adolescents. Cross-Cultural Research, 44,239-252.

8. Rohner, R. P., Uddin, M. K., Shamsunaher, M., \& Khaleque, A. (2008) Intimate partner acceptance, parental acceptance in childhood, and psychological adjustment among Japanese adults. In R. P. Rohner \& T. Melendez (Eds.), Cross Cultural Research, 42(1), 87-97.
This work is licensed under Creative Commons Attribution 4.0 License

To Submit Your Article Click Here: Submit Manuscript
Ready to submit your research? Choose Auctores and benefit from:

* fast, convenient online submission
rigorous peer review by experienced research in your field
*apid publication on acceptance
* authors retain copyrights
* immique DOI for all articles

At Auctores, research is always in progress.

Learn more www.auctoresonline.org/journals/clinical-medical-reviewsand-reports 